\title{
Bone Artefacts from Liang Lemdubu and Liang Nabulei Lisa, Aru Islands
}

Juliette Pasveer

Department of Archaeology and Natural History, Research School of Pacific and Asian Studies, The Australian National University, Canberra, ACT, Australia

\section{Introduction}

Bone artefacts in the form of small bipoints, slender unipointed specimens and spatulae, have been found in many sites throughout Australasia and Oceania. They were more common during the Holocene, but certainly also occurred during Late Pleistocene times. Due to their perishable nature and often limited modification, many may have been lost or gone unrecognised in existing assemblages. In some instances, the manufacture and use of bone artefacts through time may have been as common as that of stone tools (Webb and Allen 1990).

Systematic studies on bone points from this region have been carried out only occasionally (e.g. Lampert 1966, 1971; Olsen and Glover 2004; Pasveer 2004; Pasveer and Bellwood 2004; Pickering 1979; Webb 1987). Most individual assemblages are too small to make such analyses worthwhile. However, the few systematic studies have shown the potential of these artefacts to provide insight into their specific function and the mode of occupation of the particular site or region.

The cave sites Liang Lemdubu and Liang Nabulei Lisa produced small and highly variable bone artefact assemblages which are discussed here. The compositional similarities to assemblages from neighbouring areas offer possibilities for wider regional comparisons.

\section{The Context}

The geographical context of the two sites has been described by O'Connor et al. (Chapters 6 and 8 , this volume). Lemdubu was inhabited during the period of the Last Glacial Maximum, as well as through the subsequent period of sea level transgression that ultimately formed the islands as they were cut off from New Guinea and Australia. Analysis of the faunal remains from both sites has 


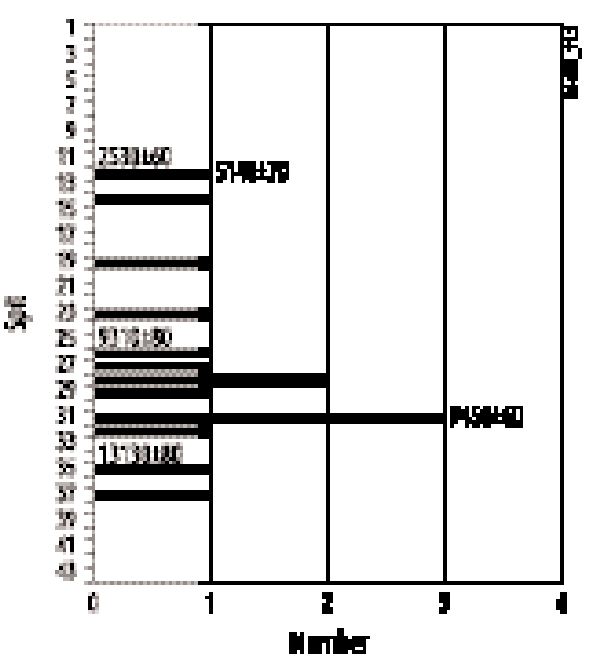

Figure 11.1 Liang Nabulei Lisa: distribution of bone artefacts through the deposit

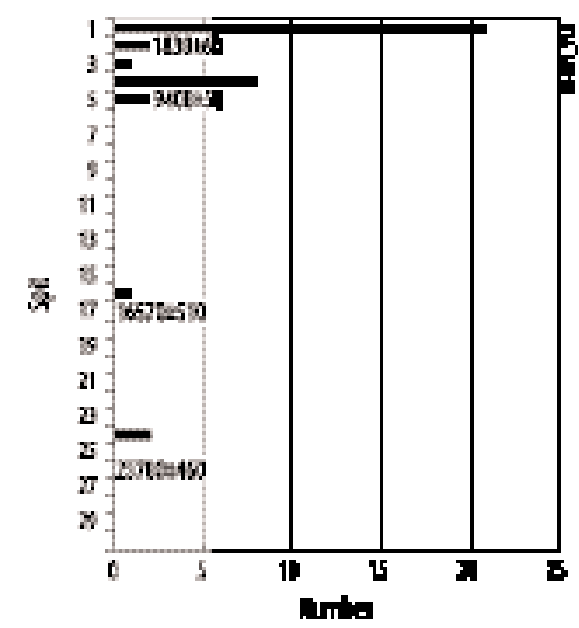

Figure 11.2 Liang Lemdubu: distribution of bone artefacts through the deposit provided a detailed picture of environmental changes and the pattern of exploitation of animal resources through time (see Chapters 3, 7 and 9, this volume).

In Nabulei Lisa (see Chapter 7, this volume), bone artefacts were found in small numbers but consistently between Spit 12 and Spit 37. There are a total of 15 specimens, with a peak occurrence in Spit 28 and Spit 31 (see Fig. 11.1). The first 10 spits in this cave probably represent the last 1000 years. Spits 11-23 produced dates between ca. 7000 and $2500 \mathrm{BP}$ (uncalibrated), and the remainder of the deposit is dated between 13,000 and 9000 BP. Eleven out of the 15 artefacts in Nabulei Lisa are thus dated roughly between 13,000 and $9000 \mathrm{BP}$.

In total, 37 bone implements were recovered from Lemdubu. The specimens were found predominantly in the top five spits (see Fig. 11.2). The majority $(\mathrm{N}=21)$ come from Spit 1 , i.e. the first five centimetres. The numbers fall progressively in lower levels, with a slight return in Spit 4. Interestingly, virtually no modified bone was found below Spit 5, except for one specimen in Spit 16 and two artefacts in Spit 24.

As described by O'Connor et al. (Chapter 9, this volume), the first three spits of Lemdubu are dated roughly to the last 2000 years (uncalibrated). Spits 5-10 produced a number of dates between ca. 12,000 and 8000 BP. However, faunal analysis shows that Spit 5 shares broad similarities to the upper four spits, including the presence of pig bone, suggesting that some mixing of younger and older material has probably occurred in this spit. Spits 17-26 date roughly around 17,000 BP, with a flowstone in Spit 26 of ca. 27,000-26,000 years old; the artefact from Spit 16 is presumably younger than 17,000 BP. The bone artefacts from Spit 24 may be assumed to date to around 18,000-17,000 BP.

The three specimens found in these deeper levels in Lemdubu seem somewhat anomalous. However, they are probably not very much older than some of the lowermost examples from Nabulei Lisa. Moreover, while the majority of bone implements reported from the wider Australasian and New Guinean region are of latest Pleistocene and Holocene age, small numbers of bone points have been found in much older contexts e.g. Devil's Lair in Western Australia (Dortch 1984:59-60), Bone Cave in south Tasmania (Webb and Allen 1990:75), and Niah Cave in Sarawak (Majid 1982). In this wider context, the presence of bone artefacts in these spits is not so extraordinary. Indeed, what is more surprising is that they are absent from the remainder of the sequence, prior to the latest Holocene. 


\section{Methods}

In several recent analyses of bone artefacts from sites in northern Maluku (Pasveer and Bellwood 2004) and the Bird's Head of Papua (Pasveer 2004), I have employed a uniform approach to describe variation in raw material, manufacture and evidence for use of these often neglected classes of artefacts. The methods are similar to those employed by many lithic analysts, and emphasize aspects of raw material selection, methods of modification, basic metric attributes, the morphology of functional edges or points and patterns of use-wear and damage. To increase comparability, the same methods were followed for the two Aru collections, although not all aspects could be analysed due to the high degree of variability of these assemblages.

Although I have tried to avoid a strictly typological approach in favour of one that emphasizes aspects of technology and function, I have nonetheless found it useful to distinguish several 'classes' of bone artefacts within the assemblages, based on their basic morphology.

\section{Descriptive terminology}

In this study, a bone artefact is defined as a piece of bone showing evidence of human modification other than simple breakage. The following attributes were recorded for each artefact:

\section{Shape}

Three broad categories were distinguished on the basis of location and type of modification together with evidence of use. Elongate artefacts with an attenuate point at one end only are classed as 'attenuate unipoints'. 'Bipoints' are attenuate and taper to points at both ends. A third, clearly recognisable class is 'spatulae', distinguished by their broad, rounded tip. Spatulae are generally modified at one end only and thus might also be viewed as a subclass of unipoints.

A fourth, loosely defined 'class' consists of what might be termed 'expedient' tools (after Pickering 1979); these show evidence of use but only minimal or no modification prior to use. Expedient tools can include unipointed or bipointed examples, or fragments thereof. Specimens that might be regarded as 'unfinished', recognisable from their limited modification and no evidence of use, are absent from the Aru assemblages.

\section{Breakage}

Fragments of bone artefacts were classified as broken bipoints if they showed obvious signs of tapering at both ends. However, short fragments with no sign of distal tapering at the other end (usually short isolated tips) might be either fragments of attenuate unipoints or bipoints broken at or before their midpoint. These fragments were scored as 'broken uni- or bipoints'. Fragments that are clearly modified and/or used but have lost both ends, and show no tapering towards the broken ends are classified as midsections (despite the fact that one end could potentially be the original butt). All breaks were recorded as either pre- or post-excavation in origin, based on the nature of the fracture surface (stained or encrusted versus fresh).

\section{Raw material}

Two types of bone were used for artefact manufacture - 'cortical': splinters of cortical bone derived from larger long bones of medium-sized to large mammals; or 'shaft': sections of small, narrow shaft bones that retain an intact (or partially intact) medullary canal (e.g. fibula, radius, wing elements of bats, typically bones from smaller mammals). 


\section{Burning state of the raw material}

Many of the artefacts are manufactured from bone that has been subjected to some degree of heating or burning. Four states are recognized, drawing on previous classifications by Ubelaker (1978), Shipman et al. (1984), and Pearce and Luff (1994):

1) Unburnt (bone is pale, yellow to light brown and porous);

2) Lightly burnt (bone is light brown to dark brown and more dense in texture; this is usually the result of cooking of the bone inside a fleshed carcass rather than direct contact with flames);

3) Burnt (bone is very dark brown or dark grey to black and very dense, usually resulting from direct contact with flame); and

4) Calcined (bone is grey to white, very dense and sometimes crazed or warped; all organic material has been lost, resulting in shrinkage and increased brittleness).

\section{Method of manufacture}

Three main techniques can be distinguished. Some artefacts show evidence of more than one method:

1) Cutting (presumably with a stone flake; resulting in wide, flat surfaces with few striations);

2) Shaving (presumably with a stone flake or retouched flake; resulting in semi-regular, linear striations, generally oriented in one direction but with complex patterns of intersection and overlay);

3) Grinding (presumably on a fine-grained sedimentary or metamorphic rock; resulting in flat facets with fine, parallel and generally non-intersecting striations).

\section{Use polish}

Many specimens bear localised polish at one or both of their pointed ends. In other cases the polish is more generalized and occurs as a light gloss over much of the bone surface. Four 'degrees' of polish were recorded: no polish, light polish, medium polish, and high polish. The degree of polish present was recorded separately for each end of a bipoint.

\section{Tip damage}

This refers to localised damage to the tip of an artefact, and is distinguished from an actual break. At least some of the tip damage probably results from use of the artefacts, although some damage might also have occurred following discard. Five categories of damage were recorded for each tip:

1) Intact (i.e. no damage);

2) Snap fracture (usually transverse);

3) Step fracture (directed along the length of the artefact and often hinged at its termination);

4) Crushing; and

5) 'Complex' (usually ragged, possibly multiple step fractures or a combination of step and snap fractures).
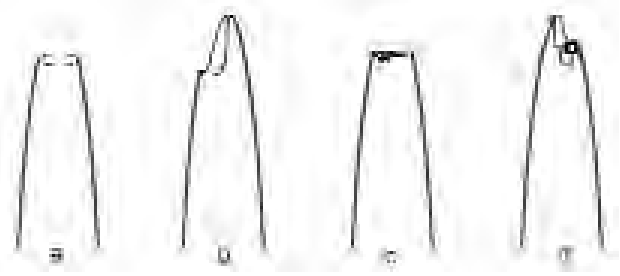

Figure 11.3 Types of damage found at the tip of bone artefacts: a) snap-fracture b) step-fracture c) crushing and d) multiple types of damage ('complex')
Each category is exemplified in Figure 11.3. Similar kinds of damage have been described on the tips of bone and antler artefacts by other researchers (e.g. Arndt and Newcomer 1986; Campana 1989; Johnson 1985; Olsen 1984).

Bone collections inevitably suffer some damage during excavation and subsequent storage. This is easily recognized by the lighter colour of the fractured surface and by the lack of soil or calcium carbonate attached to this surface. However, damage that occurs during manufacture or use cannot be 
distinguished from post-depositional damage. Breakage of bone artefacts after discard or loss, for example by trampling by the occupants of the cave or by other taphonomic processes, can strongly bias the breakage frequency caused by manufacturing or actual use. This problem will be discussed where necessary in this paper.

\section{Additional modification}

A small number of specimens from the northern Maluku and Bird's Head sites were clearly burnt after manufacture; this has not been observed on the Aru artefacts.

Although the bone artefacts studied here were collected by the editors of this volume and by their excavation team, as well as by the author during subsequent sorting of the faunal assemblages, it is possible that fragments such as isolated tips may have been missed. However, it is believed that the majority of the bone artefacts were recovered.

\section{Measurements}

The Aru bone artefacts have been measured following the system used for the northern Maluku and Bird's Head specimens. However, due to the highly variable nature of the assemblages, there is little value in a metrical or statistical analysis. The raw data of the artefacts are presented in Tables 11.8 and 11.9.

The following measurements (see Fig. 11.4) were taken on all bone artefacts with a vernier calliper, to a precision of $0.1 \mathrm{~mm}$ :

1) Maximum length: no attempt was made to correct for minor damage that has affected the tip of many otherwise complete specimens. This damage has removed no more than an estimated $1-2 \mathrm{~mm}$ of the artefact.

2) Width and thickness: taken perpendicular to each other and at the same position on the artefact. The width and the thickness of each artefact were defined in relation to the greatest width of the tip. For attenuate unipoints the width and thickness were measured at the base of the point/modified area. However, in some heavily modified specimens the boundary between the point and the shaft of the artefact is unclear; in such cases the measurements were taken at the widest or thickest point of the artefact. For most specimens, the width exceeded the thickness, but the opposite was true for some nearly circular shaft bones. For bipoints the width and thickness were measured at the widest point of the artefact.

3) Point length: with the 'point' defined as the zone of modification or, in specimens showing general modification, as the distance from the tip to the widest point on the artefact. For intact bipoints, point length was measured for the primary end (the end with the most polish and/or damage), with the length of the secondary end being obtained by subtraction from the maximum length. If the point had broken through the zone of modification, the point length would be the same as the maximum length of the fragment, although the original point length of the artefact is likely to have been longer.

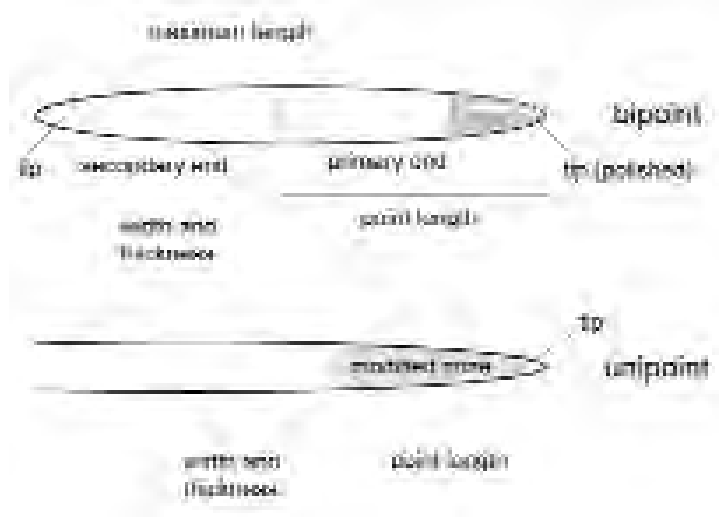

Figure 11.4 Liang Lemdubu and Liang Nabulei Lisa: descriptive terminology and measurements of bone artefacts 


\section{Description of the Artefacts}

A total of 52 bone artefacts were found in the two cave sites on Aru: 37 in Liang Lemdubu and 15 in Liang Nabulei Lisa (see Figs 11.5 and 11.6 for examples from each assemblage). Both sites produced highly variable assemblages, containing various unipointed artefacts and spatulae, or fragments thereof. Only one bipointed artefact was found, from Nabulei Lisa.

\section{Liang Lemdubu}

Liang Lemdubu did not provide any complete bipointed specimens, but there are 21 short unipointed fragments that are parts of broken uni- or bipoints. Only two artefacts could be classified as attenuate unipoints with some confidence considering their length, narrow width and lack of tapering towards the butt. Three specimens have a broad, rounded tip and are classified as spatulae. Five specimens that have lost one or both ends, but which show clear modification

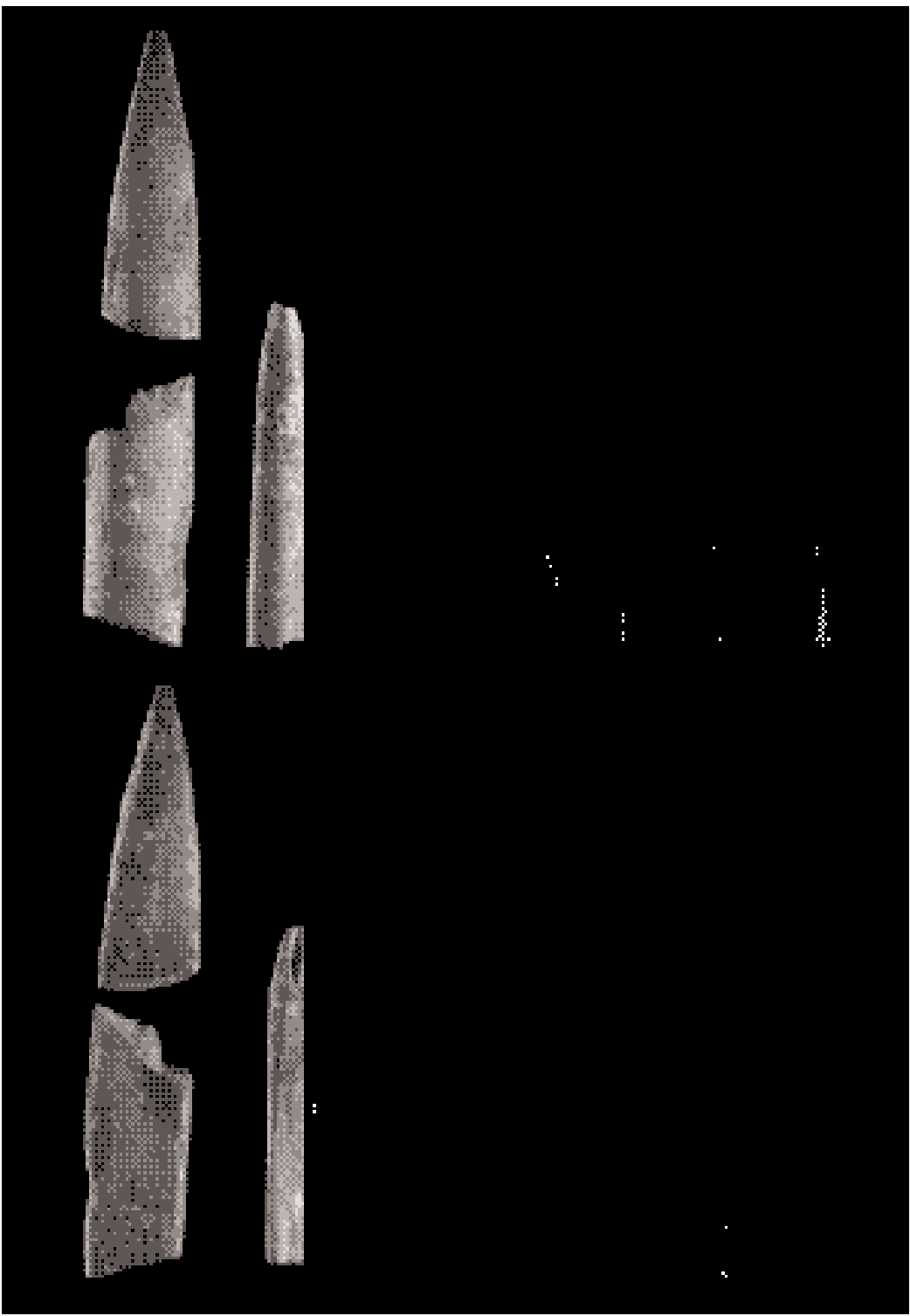

Figure 11.5 Liang Lemdubu: examples of bone artefacts. From left to right: specimen numbers LL4h (broken uni- or bipoint); LC2a (unipoint); LC1C (spatula fragment); LC1d (spatula fragment); LC1i (broken uni- or bipoint); LC1b (broken uni- or bipoint); LC5b (broken uni- or bipoint) marks, form the midsection of attenuate unipoints, bipoints or spatulae. The assemblage also includes six fragments (again midsections) of bone from Spit 1 with varying degrees of polish suggestive of use. Because these specimens show no clear indications of modification, they are classified as parts of potential 'expedient tools'. However, the incomplete state of these artefacts is a cause for doubt as to their true nature.

Almost three-quarters $(70 \%)$ of the artefacts were made from fragments of small shaft bones (Table 11.1). Several of these are recognisable as the central and distal sections of wallaby fibulae, including both Thylogale sp. and Macropus agilis (Agile Wallaby). The remaining artefacts, including broken uni- or bipoints and one spatulate tool, were made of fragments of cortical bone of various unidentified mammals.

A large proportion $(54 \%)$ of the raw material that was used for artefact manufacture consisted of lightly 
burnt bone (Table 11.2); $27 \%$ of the artefacts were made of unburnt bone, and eight per cent of burnt bone. Four specimens are calcined, but show no sign of warping or other distortion. Even though it cannot be excluded that they were made originally from calcined bone, it seems more likely that they have become calcined after discard. In general, intense heating or burning of bone has no advantages for bone modification, as the material becomes increasingly brittle (Campana 1989). None of the artefacts showed secondary burn marks, such as were observed on some bone artefacts from Kria Cave on the Bird's Head Peninsula of Papua (Pasveer 2004:152, 167).

Most of the artefacts showed the finely striated, regular facets produced by grinding (Table 11.3). In some cases they were cut or shaved before being ground into their present shape. Although cut and shaving marks are in some cases somewhat obscured by the subsequent grinding, the earlier phase of modification is usually recognisable from the deeper, irregular striations produced by a stone tool, or by a straight cutting plane. However, it cannot be ruled out that cutting planes, shaving marks, or even grinding facets may have been obliterated by subsequent modification or use.

\section{Shaft artefacts: attenuate unipoints}

One of the two artefacts that were classified as a potential attenuate unipoints shows a slight gloss over its entire surface, but it is otherwise unpolished. The tip was damaged during or after excavation. The butt was evidently snapped off at some stage in antiquity. The length of the artefact is $27.8 \mathrm{~mm}$ but it may have once been longer. The point length is $6.3 \mathrm{~mm}$; its width is five millimetres and its thickness is $3.2 \mathrm{~mm}$ (see Table 11.8). It was made of the central part of a Thylogale fibula; the medullary canal is visible at one side of the tip (specimen LC2a, Fig. 11.5).

The other attenuate unipoint is unpolished and has an undamaged tip. It is $28.7 \mathrm{~mm}$ long, $4.2 \mathrm{~mm}$ wide, and $2.7 \mathrm{~mm}$ thick, with a point length of $14.2 \mathrm{~mm}$. It was ground into its present shape and was also made from the central part of a Thylogale fibula.

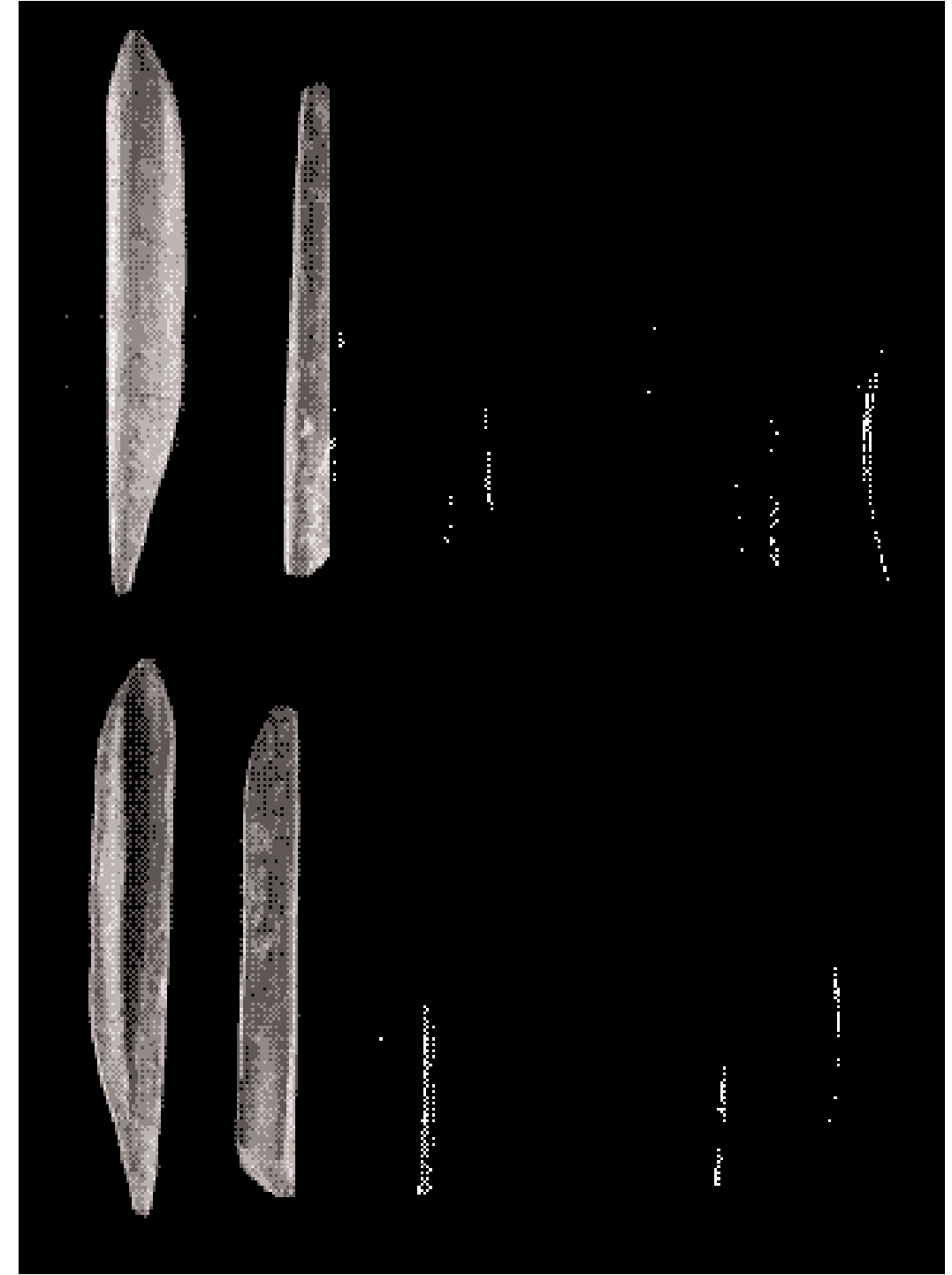

Figure 11.6 Liang Nabulei Lisa: examples of bone artefacts. From left to right: specimen numbers NL/I/29a (bipoint); NL/I/37a (unipoint); NL/I/27a (unipoint); $\mathrm{NL} / \mathrm{I} / 23 a$ (spatula); NL/I/14a (spatula fragment); NL/I/28a (expedient tool) 
Table 11.1 Liang Lemdubu and Liang Nabulei Lisa: type of raw material used for the various bone artefacts

\begin{tabular}{|c|c|c|c|c|c|c|}
\hline & \multicolumn{3}{|c|}{ LEMDUBU } & \multicolumn{3}{|c|}{ NABULEI LISA } \\
\hline & SHAFT & CORTICAL & TOTAL & SHAFT & CORTICAL & TOTAL \\
\hline Attenuate unipoints & 2 & - & 2 & 2 & - & 2 \\
\hline Bipoints & - & - & - & 1 & - & 1 \\
\hline Broken uni- or bipoints & 11 & 10 & 21 & 5 & 3 & 8 \\
\hline Spatulae & 2 & 1 & 3 & 2 & - & 2 \\
\hline Midsections & 5 & - & 5 & 1 & - & 1 \\
\hline Expedient tools? & 6 & - & 6 & 1 & - & 1 \\
\hline Total & 26 & 11 & 37 & 12 & 3 & 15 \\
\hline
\end{tabular}

Table 11.2 Liang Lemdubu and Liang Nabulei Lisa: degree of burning of raw material used for bone artefact manufacture ( $c=$ cortical; $s=$ shaft $)$

\begin{tabular}{|c|c|c|c|c|c|c|c|c|c|c|c|c|c|c|c|c|c|}
\hline & & & & & & MDU & & & & & & & & NABULEI & LISA & & \\
\hline & UNB & JRNT & LIGHTL & Y BURNT & BURI & 2NT & CALC & INED & TO & TAL & UNBU & RNT & LIGHTLY & Y BURNT & BUR & & TOTA \\
\hline & c & s & c & s & $c$ & s & c & s & $c$ & $s$ & c & s & $c$ & $s$ & c & $s$ & c s \\
\hline Attenuate unipoints & 1 & 1 & - & 1 & - & - & - & - & - & 2 & - & 1 & - & 1 & - & - & -2 \\
\hline Bipoints & - & - & - & - & - & - & - & - & - & - & - & 1 & - & - & - & - & - \\
\hline Broken uni- or bipoints & 3 & 5 & 5 & 3 & 1 & - & 1 & 3 & 10 & 11 & 2 & - & - & 4 & 1 & 1 & 3 \\
\hline Spatulae & 1 & - & - & 2 & - & - & - & - & 1 & 2 & - & - & - & 2 & - & - & - \\
\hline Midsections & - & - & - & 4 & - & 1 & - & - & - & 5 & - & - & - & - & - & 1 & - \\
\hline Expedient tools? & - & - & - & 5 & - & 1 & - & - & - & 6 & - & 1 & - & - & - & - & -1 \\
\hline Total & 4 & 6 & 5 & 15 & 1 & 2 & 1 & 3 & 11 & 26 & 2 & 3 & - & 7 & 1 & 2 & 312 \\
\hline
\end{tabular}

Table 11.3 Liang Lemdubu and Liang Nabulei Lisa: manufacturing techniques used in bone artefact production ( $c=c o r t i c a l ;$ $s=$ shaft)

\begin{tabular}{|c|c|c|c|c|c|c|c|c|c|c|c|c|c|c|c|c|c|c|c|c|}
\hline & \multicolumn{8}{|c|}{ LEMDUBU } & \multicolumn{12}{|c|}{ NABULEI LISA } \\
\hline & \multicolumn{2}{|c|}{ GROUND } & \multicolumn{2}{|c|}{$\begin{array}{c}\text { SHAVED } \\
\text { THEN GROUND }\end{array}$} & \multicolumn{2}{|c|}{$\begin{array}{l}\text { CUT THEN } \\
\text { GROUND }\end{array}$} & \multicolumn{2}{|c|}{ TOTAL } & \multicolumn{2}{|c|}{ GROUND } & \multicolumn{2}{|c|}{$\begin{array}{c}\text { SHAVED, } \\
\text { THEN GROUND }\end{array}$} & \multicolumn{2}{|c|}{$\begin{array}{l}\text { CUT, THEN } \\
\text { GROUND }\end{array}$} & \multicolumn{2}{|c|}{ SHAVED } & \multicolumn{2}{|c|}{ UNKNOWN" } & \multicolumn{2}{|c|}{ TOTAL } \\
\hline & C & $S$ & c & $S$ & C & $s$ & c & $S$ & c & $s$ & C & $s$ & c & $S$ & c & $s$ & C & $s$ & c & $s$ \\
\hline Attenuate unipoints & - & 1 & - & 1 & - & - & - & 2 & - & 1 & - & 1 & - & - & - & - & - & - & - & 2 \\
\hline Bipoints & - & - & - & - & - & - & - & - & - & - & - & 1 & - & - & - & - & - & - & - & 1 \\
\hline Broken uni- or bipoints & 6 & 8 & 2 & 2 & - & 1 & 8 & 11 & - & 1 & 1 & 3 & - & 1 & 1 & - & 1 & - & 3 & 5 \\
\hline Spatulae & 1 & 2 & - & - & - & - & 1 & 2 & - & 2 & - & - & - & - & - & - & - & - & - & 2 \\
\hline Midsections & - & 3 & - & 2 & - & - & - & 5 & - & - & - & 1 & - & - & - & - & - & - & - & 1 \\
\hline Total & 7 & 14 & 2 & 5 & - & 1 & 9 & 20 & - & 4 & 1 & 6 & - & 1 & 1 & - & 1 & - & 3 & 11 \\
\hline
\end{tabular}

"0n one very small broken uni- or bipoint from Nabulei Lisa no modification marks were visible

NB: six artefacts in Liang Lemdubu, and one artefact in Liang Nabulei Lisa are classified as expedient tools, i.e. used but unmodified. Two artefacts from Liang Lemdubu are encrusted and modification marks are unclear 


\section{Shaft artefacts: broken uni- or bipoints}

Eleven artefacts made of shaft bone were classified as either broken attenuate unipoints or broken bipoints. An intact tip is present at one end, but the lack of tapering at the broken end inhibits any further identification.

Seven out of 11 specimens show a light to high polish (Table 11.4), either localised at the tip or extending over the entire surface. Four artefacts show no polish at all; some merely have an overall light gloss. The majority of tips are undamaged (Table 11.5); two are somewhat crushed or blunted in antiquity and one was slightly damaged after excavation. In two-thirds of cases the broken end shows a snap fracture (Table 11.6); three artefacts showed a less specific breakage, and one has a recent break. The length of these artefacts is highly variable and ranges from 4.1-22.4mm. Some specimens are modified over their entire surface down to the point of breakage, hence the point length may originally have been longer.

\section{Shaft artefacts: midsections and expedient tools}

Eleven shaft fragments of artefacts were found which lack the tip, and possibly the butt as well, and were classified as midsections. Six of these show no signs of modification but are clearly polished, albeit with varying intensity. These artefacts are therefore assumed to have been part of expedient tools - artefacts that were simply used because of their convenient shape. The length of these artefacts ranges from $6.3-13.7 \mathrm{~mm}$. Three artefacts show snap fractures at both ends; in the other three cases step fractures were found at one end of the artefact, with the other end snapped off. In all cases the breakage occurred at some stage in antiquity.

The remaining five midsections show evidence of modification. All but one of these are also polished. The ends are either snapped off or show more complex fractures; one specimen has a step fracture at one end and less specific breakage at the other. Their length varies between $10.7-18.1 \mathrm{~mm}$.

\section{Shaft artefacts: spatulae}

Two 'shaft' spatulae were found in Liang Lemdubu. Both were made from the distal part of Thylogale fibulae and both are small fragments of the broad rounded tip (see for one example specimen LC1d, Fig. 11.5). One is highly polished at the tip, the other shows a light polish over most of its surface. One has an intact tip, the other was damaged some time before excavation and bears a large step fracture. The length, width and thickness of these fragments are very similar (L: $7.8 \mathrm{~mm}$ and eight millimetres; $\mathrm{W}: 6.8 \mathrm{~mm}$ and $6.4 \mathrm{~mm}$; $\mathrm{T}: 2.2 \mathrm{~mm}$ and $2.3 \mathrm{~mm}$, respectively), reflecting the dimensions of the parent bone. Both artefacts were ground into their present shape.

\section{Cortical artefacts: broken uni- or bipoints}

The majority of cortical artefacts (10 out of 11) were classified as broken uni- or bipoints. Seven out of these 10 specimens show definite polish to varying intensity (Table 11.4); the others are somewhat glossy, although probably not as a result of use. In four cases the tip was undamaged (Table 11.5). Three of the damaged specimens show a somewhat crushed or blunted tip. The others have a step fracture, a snap fracture and more complex damage. The broken end was in most cases snapped off (Table 11.6); in one artefact a step fracture caused the breakage, and the remaining specimens showed more complex damage. Their length ranges from 6.1-17.2mm; however, one very large specimen (in two parts), with a length of $44.6 \mathrm{~mm}$, is also included in this category on account of its exceptional width (specimen LC4h, Fig. 11.5). Width and thickness vary between $3.2-8.0 \mathrm{~mm}(\mathrm{~W})$ and $1.1-3.3 \mathrm{~mm}(\mathrm{~T})$. The point length of the broken uni- or bipoints ranges from $4.9-17.2 \mathrm{~mm}$. Some of the points might originally have been longer as the modification marks run across the breakage. 
Table 11.4 Liang Lemdubu and Liang Nabulei Lisa: variation in polish found across artefact categories (c=cortical; s=shaft)

\begin{tabular}{|c|c|c|c|c|c|c|c|c|c|c|c|c|c|c|c|}
\hline & \multicolumn{8}{|c|}{ LEMDUBU } & \multicolumn{7}{|c|}{ NABULEI LISA } \\
\hline & \multicolumn{2}{|c|}{$\begin{array}{c}\text { NO } \\
\text { POLISH }\end{array}$} & \multicolumn{2}{|c|}{$\begin{array}{c}\text { LIGHT } \\
\text { POLISH }\end{array}$} & \multicolumn{2}{|c|}{$\begin{array}{l}\text { MEDIUM } \\
\text { POLISH }\end{array}$} & \multicolumn{2}{|c|}{$\begin{array}{c}\text { HIGH } \\
\text { POLISH }\end{array}$} & \multicolumn{2}{|c|}{$\begin{array}{c}\text { NO } \\
\text { POLISH }\end{array}$} & \multicolumn{2}{|c|}{$\begin{array}{l}\text { LIGHT } \\
\text { POLISH }\end{array}$} & \multicolumn{2}{|c|}{$\begin{array}{c}\text { MEDIUM } \\
\text { POLISH }\end{array}$} & \multirow{2}{*}{$\begin{array}{l}\text { HIGH } \\
\text { POLISH } \\
\text { C S }\end{array}$} \\
\hline & c & s & c & s & c & $s$ & c & s & c & s & c & s & c & $s$ & \\
\hline Attenuate unipoints & - & 2 & - & - & - & - & - & - & - & 2 & - & - & - & - & -1 \\
\hline Bipoints & - & - & - & - & - & - & - & - & - & - & - & 1 & - & - & -- \\
\hline Broken uni- or bipoints & 3 & 4 & 1 & 3 & 3 & 2 & 3 & 2 & 2 & 2 & - & 1 & 1 & - & -2 \\
\hline Spatulae & - & - & 1 & 1 & - & - & - & 1 & - & - & - & - & - & - & -2 \\
\hline Midsections & - & 1 & - & 1 & - & 1 & - & 2 & - & 1 & - & - & - & - & -- \\
\hline Expedient tools? & - & - & - & 4 & - & - & - & 2 & - & - & - & - & - & - & -- \\
\hline Total & 3 & 7 & 2 & 9 & 3 & 3 & 3 & 7 & 2 & 5 & - & 2 & 1 & - & -5 \\
\hline
\end{tabular}

Table 11.5 Liang Lemdubu and Liang Nabulei Lisa: type of tip damage found across artefact categories (c=cortical; $s=s h a f t)$

\begin{tabular}{|c|c|c|c|c|c|c|c|c|c|c|c|c|c|c|c|c|c|c|c|}
\hline & \multicolumn{11}{|c|}{ LEMDUBU } & \multicolumn{8}{|c|}{ NABULEI LISA } \\
\hline & \multicolumn{3}{|c|}{ SNAP } & $\begin{array}{l}\text { AP } \\
\text { TURE }\end{array}$ & STEP & $\begin{array}{l}\text { EP } \\
\text { TURE }\end{array}$ & \multicolumn{2}{|c|}{ CRUSHED } & COMI & IPLEX & $\begin{array}{c}\text { POST- } \\
\text { EXCAVATION }\end{array}$ & \multicolumn{2}{|c|}{ INTACT } & \multicolumn{2}{|c|}{$\begin{array}{c}\text { SNAP } \\
\text { FRACTURE }\end{array}$} & \multicolumn{2}{|c|}{$\begin{array}{c}\text { STEP } \\
\text { FRACTURE }\end{array}$} & CRUSHED & COMPLEX \\
\hline & $c$ & s & c & $s$ & $c$ & s & $c$ & $s$ & c & $\mathrm{s}$ & C S & c & $s$ & c & $\mathrm{s}$ & $c$ & $s$ & C S & C $s$ \\
\hline Attenuate unipoints & - & 1 & - & - & - & - & - & - & - & - & -1 & - & - & - & - & - & - & -1 & -1 \\
\hline Bipoints & - & - & - & - & - & - & - & - & - & - & -- & - & $1^{*}$ & - & - & - & - & -- & -- \\
\hline Broken uni- or bipoints & 4 & 8 & 1 & - & 1 & - & 3 & 2 & 1 & - & -1 & 2 & 4 & - & - & - & 1 & -- & $1-$ \\
\hline Spatulae & - & 1 & - & - & - & 1 & - & - & 1 & - & - & - & 2 & - & - & - & - & - & -- \\
\hline Expedient tools & - & - & - & - & - & - & - & - & - & - & -- & - & - & - & 1 & - & - & -- & -- \\
\hline Total & 4 & 10 & 1 & - & 1 & 1 & 3 & 2 & 2 & - & -2 & 2 & 7 & - & 1 & - & 1 & -1 & 11 \\
\hline
\end{tabular}

"Both ends intact

Table 11.6 Liang Lemdubu and Liang Nabulei Lisa: type of breakage found across artefact categories (c=cortical; s=shaft)

\begin{tabular}{|c|c|c|c|c|c|c|c|c|c|c|c|c|c|c|c|c|c|c|c|c|c|c|}
\hline & \multicolumn{10}{|c|}{ LEMDUBU } & \multicolumn{12}{|c|}{ NABULEI LISA } \\
\hline & \multicolumn{2}{|c|}{$\begin{array}{c}\text { SNAP } \\
\text { FRACTURE }\end{array}$} & \multicolumn{2}{|c|}{ STEP } & \multicolumn{2}{|c|}{ CRUSHED } & \multicolumn{2}{|c|}{ COMPLEX } & \multicolumn{2}{|c|}{$\begin{array}{c}\text { POST- } \\
\text { EXCAVATION }\end{array}$} & \multicolumn{2}{|c|}{ INTACT } & \multicolumn{2}{|c|}{$\begin{array}{c}\text { SNAP } \\
\text { FRACTURE }\end{array}$} & \multicolumn{2}{|c|}{$\begin{array}{c}\text { STEP } \\
\text { E FRACTURE }\end{array}$} & \multicolumn{2}{|c|}{ CRUSHED } & \multicolumn{2}{|c|}{ COMPLEX } & \multicolumn{2}{|c|}{$\begin{array}{c}\text { POST- } \\
\text { EXCAVATION }\end{array}$} \\
\hline & c & s & c & $s$ & $c$ & s & c & $s$ & $c$ & s & $c$ & s & $\mathrm{C}$ & s & $c$ & $s$ & $c$ & s & $c$ & $s$ & & s \\
\hline Attenuate unipoints & - & 1 & - & - & - & - & - & 1 & - & - & - & - & - & 1 & - & 1 & - & - & - & - & - & - \\
\hline Bipoints & - & - & - & - & - & - & - & - & - & - & - & $1^{*}$ & - & - & - & - & - & - & - & - & - & - \\
\hline Broken uni- or bipoints & 5 & 7 & 1 & - & - & - & 3 & 3 & 1 & 1 & - & - & 1 & 3 & - & 2 & - & - & 1 & - & 1 & - \\
\hline Spatulae & - & 1 & - & - & - & - & 1 & 1 & - & - & - & - & - & 1 & - & - & - & - & - & 1 & - & - \\
\hline Midsections end 1 & - & 2 & - & 1 & - & - & - & 2 & - & - & - & - & - & - & - & - & - & - & - & 1 & - & - \\
\hline Midsections end 2 & - & 2 & - & - & - & - & - & 3 & - & - & - & - & - & - & - & - & - & - & - & 1 & - & - \\
\hline Expedient tools? end 1 & - & 3 & - & 3 & - & - & - & - & - & - & - & - & - & - & - & - & - & - & - & - & - & - \\
\hline Expedient tools? end 2 & - & 6 & - & - & - & - & - & - & - & - & - & - & - & - & - & - & - & - & - & 1 & - & - \\
\hline
\end{tabular}

"Both ends intact

NB: the breakage at the butt-end of the artefact may or may not represent the artefact's original 'end'

\section{Cortical artefacts: the spatula}

One spatula made from unidentified cortical bone has a similar morphology to those made of Thylogale fibula (specimen LC1c, Fig. 11.5). However, it is slightly wider and thinner than the fibula specimens ( $7.4 \mathrm{~mm}$ and $1.9 \mathrm{~mm}$ respectively), and shows a light polish over its surface. Its rounded tip was slightly damaged in antiquity with a complex fracture. Like the fibula spatulae, it was ground into its present shape. 


\section{Liang Nabulei Lisa}

The bone artefacts from Liang Nabulei Lisa show a large variation in size and shape (see Fig. 11.6, Table 11.9). A total of 15 specimens were found, all but one of which were definitely modified. The one exception is a bone that bears high polish but otherwise shows no modification and thus is classified as an expedient tool. Two artefacts are classified as attenuate unipoints considering their total length, relatively narrow width and lack of tapering at the butt. There is only one bipoint in this collection, and also only one midsection. Eight artefacts are classified as broken uni- or bipoints because their short length and lack of tapering at the broken end precludes more precise identification. The remaining two artefacts have the typical rounded tips of spatulae. The majority of the artefacts were made of fragments of small mammalian shaft bones, most of which could not be further identified to taxon. However, recognisable Thylogale fibula fragments and a snake rib are included among them.

Almost half of the artefacts were made of lightly burnt bone (Table 11.2); five were made of unburnt bone and three of burnt bone. Calcined artefacts were not found. None of the artefacts showed secondary burn marks, which would have indicated burning after discard.

Seven of the 14 modified artefacts were first shaved and then ground into shape, and one was cut and then ground (Table 11.3). This is a larger proportion than present in the assemblage from Liang Lemdubu. Four artefacts were ground only, and one was shaved only. As for Lemdubu, grinding facets were evident on many of the artefacts. Earlier shaving marks were recognised as irregular striations, often somewhat obscured by subsequent grinding. Again, in all cases, cutting planes, shaving marks, or even grinding facets may have been obliterated by subsequent modification or use. One tiny isolated tip fragment proved too small to determine its mode of manufacturing.

\section{Shaft artefacts: attenuate unipoints}

Three attenuate unipoints were found at the site; one of these is classified as an expedient tool, which will be discussed below. The other two specimens are $34.3 \mathrm{~mm}$ and $38 \mathrm{~mm}$ in length, measuring $5.1 \mathrm{~mm}$ and $4.6 \mathrm{~mm}$ in width, and $2.9 \mathrm{~mm}$ and $2.5 \mathrm{~mm}$ in thickness, respectively. The longer unipoint (specimen NL/I/37a, Fig. 11.6) has a point length of $5.8 \mathrm{~mm}$; the shorter unipoint (specimen NL/I/27a, Fig. 11.6) is modified all over its surface so the boundary of the tip is difficult to establish. The tip of NL/I/27a shows some complex damage, and the butt was snapped off. Specimen NL/I/37a has a rather blunted tip and a large step fracture at the butt. Both artefacts showed only very light polish, probably caused by handling rather than use.

Table 11.7 Liang Lemdubu and Liang Nabulei Lisa: relationship between damage and polish. Specimens showing postexcavation damage are excluded (shaft and cortical bone combined)

\begin{tabular}{|c|c|c|c|c|c|}
\hline & \multicolumn{5}{|c|}{ LEMDUBU } \\
\hline & NO DAMAGE & SNAP FRACTURE & STEP FRACTURE & CRUSHING & COMPLEX \\
\hline No polish & 5 & 1 & & 3 & \\
\hline Light polish & 3 & 3 & 3 & 1 & 1 \\
\hline Medium polish & 3 & 1 & 1 & & \\
\hline \multirow[t]{3}{*}{ High polish } & 3 & 1 & 2 & 1 & 3 \\
\hline & \multicolumn{5}{|c|}{ NABULEI LISA } \\
\hline & NO DAMAGE & SNAP FRACTURE & STEP FRACTURE & CRUSHING & COMPLEX \\
\hline No polish & 2 & & 1 & 1 & 3 \\
\hline Light polish & 2 & & & & \\
\hline Medium polish & 1 & & & & \\
\hline High polish & 4 & 1 & & & \\
\hline
\end{tabular}




\begin{tabular}{|c|c|c|c|c|c|c|c|c|c|c|c|c|c|c|}
\hline 总 & $\overline{\bar{\Delta}}$ & 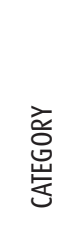 & 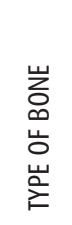 & 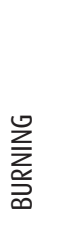 & 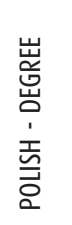 & 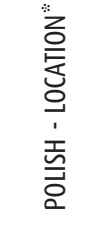 & 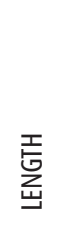 & $\frac{\text { 豆 }}{3}$ & 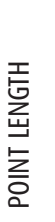 & 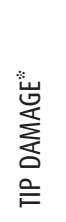 & 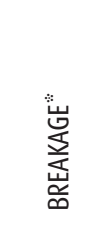 & 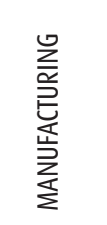 & $\begin{array}{l}\text { 岂 } \\
\text { 을 } \\
\text { 总 }\end{array}$ & $\begin{array}{l}\text { 岕 } \\
\text { ڤ્ڤ }\end{array}$ \\
\hline LC1a & 1 & mid & shaft & $\mathrm{lb}$ & light & one end & 14.1 & 7.8 & 4.5 & & snap fr & snap fr & $\mathrm{sh} / \mathrm{gr}$ & mammal \\
\hline LC1b & 1 & $1 / 2 b$ & cort & $\mathrm{lb}$ & high & tip & 13.6 & 4.4 & 2.3 & 13.6 & complex & snap fr & gr & mammal \\
\hline LC1C & 1 & spat & cort & $u$ & light & ent surf & 7.7 & 7.4 & 1.9 & 7.7 & complex & complex & gr & mammal \\
\hline LC1d & 1 & spat & shaft & $\mathrm{lb}$ & high & tip & 7.8 & 6.8 & 2.2 & 4.8 & intact & complex & gr & $\begin{array}{l}\text { Thylogale } \\
\text { distal fibula }\end{array}$ \\
\hline LC1e & 1 & $1 / 2 b$ & cort & $\mathrm{lb}$ & high & tip & 9.7 & 4.5 & 1.1 & 9.7 & crushed & snap fr & $\mathrm{sh} / \mathrm{gr}$ & mammal \\
\hline LC1f & 1 & $1 / 2 b$ & cort & $\mathrm{lb}$ & med & ent surf & 16.3 & 4.4 & 2.4 & 16.3 & snap fr & step fr & gr & mammal \\
\hline LC1g & 1 & mid & shaft & $b$ & high & one end & 18.1 & 4.1 & 2.9 & & complex & complex & gr & $\begin{array}{l}\text { Thylogale mid } \\
\text { part fibula }\end{array}$ \\
\hline LC1h & 1 & mid & shaft & $\mathrm{lb}$ & med & ent surf & 11.1 & 3.2 & 1.8 & & step fr & complex & sh/gr & mammal \\
\hline LC1i & 1 & $1 / 2 b$ & shaft & $u$ & no & & 9.7 & 2.2 & 1.6 & 9.7 & intact & post-exc & gr & mammal \\
\hline LC1j & 1 & $1 / 2 b$ & shaft & u & high & ent surf & 8.3 & 2.6 & 1.9 & 8.3 & intact & snap fr & gг & mammal \\
\hline LC1k & 1 & $1 / 2 b$ & shaft & $u$ & med & ent surf & - & 2.8 & 2.7 & - & post-exc & complex & gr & mammal \\
\hline LC1I & 1 & mid & shaft & $\mathrm{lb}$ & high & ent surf & 11.7 & 2.1 & 2.3 & & complex & complex & gг & mammal \\
\hline LC1m & 1 & spat & shaft & $\mathrm{Ib}$ & light & ent surf & 8.0 & 6.4 & 2.3 & 8.0 & step fr & snap fr & gr & $\begin{array}{l}\text { Thylogale } \\
\text { distal fibula }\end{array}$ \\
\hline LC1n & 1 & $\exp "$ & shaft & $\mathrm{lb}$ & high & one end & 13.7 & 4.7 & 1.8 & & snap fr & snap fr & - & $\begin{array}{l}\text { Thylogale } \\
\text { distal fibula }\end{array}$ \\
\hline LC10 & 1 & exp" & shaft & $\mathrm{lb}$ & light & ent surf & 6.3 & 5.5 & 1.8 & & step fr & snap fr & - & $\begin{array}{l}\text { Thylogale } \\
\text { distal fibula }\end{array}$ \\
\hline LC1p & 1 & exp" & shaft & b & light & ent surf & 22.1 & 3.4 & 2.5 & & snap fr & snap fr & - & $\begin{array}{l}\text { Thylogale mid } \\
\text { part fibula }\end{array}$ \\
\hline LC1q & 1 & exp" & shaft & $\mathrm{lb}$ & light & ent surf & 9.8 & 3.7 & 2.3 & & snap fr & snap fr & - & mammal \\
\hline LC1r & 1 & exp" & shaft & $\mathrm{lb}$ & light & ent surf & 8.9 & 3.0 & 2.7 & & step fr & snap fr & - & mammal \\
\hline LC1s & 1 & exp" & shaft & $\mathrm{lb}$ & high & ent surf & 7.6 & 3.2 & 1.3 & & step fr & snap fr & - & mammal \\
\hline LC1t & 1 & $1 / 2 b$ & cort & $u$ & no & & 8.9 & 5.0 & 1.6 & 8.9 & intact & complex & $?$ & mammal \\
\hline LC1u & 1 & $1 / 2 b$ & cort & $u$ & no & & 9.3 & 4.5 & 1.6 & 9.3 & intact & complex & $?$ & mammal \\
\hline LC2a & 2 & 1 & shaft & $\mathrm{Ib}$ & no & & 27.8 & 5.0 & 3.2 & 6.3 & post-exc & snap fr & $\mathrm{sh} / \mathrm{gr}$ & $\begin{array}{l}\text { Thylogale mid } \\
\text { part fibula }\end{array}$ \\
\hline $\mathrm{LC} 2 \mathrm{~b}$ & 2 & $1 / 2 b$ & shaft & calc & light & ent surf & 16.1 & 4.6 & 2.6 & 5.5 & intact & snap fr & $\mathrm{sh} / \mathrm{gr}$ & $\begin{array}{l}\text { Thylogale mid } \\
\text { part fibula }\end{array}$ \\
\hline LC3a & 3 & $1 / 2 b$ & shaft & $\mathrm{lb}$ & med & tip & 11.9 & 3.5 & 3.9 & 6.6 & intact & complex & $\mathrm{sh} / \mathrm{gr}$ & mammal \\
\hline LC4a & 4 & $1 / 2 b$ & shaft & $\mathrm{Ib}$ & light & ent surf & 10.2 & 5.9 & 3.1 & 10.2 & intact & snap fr & $g r$ & $\begin{array}{l}\text { Agile Wallaby } \\
\text { distal fibula }\end{array}$ \\
\hline LC4b & 4 & $1 / 2 b$ & cort & b & med & ent surf & 6.1 & 3.2 & 1.1 & 4.9 & intact & post-exc & gr & mammal \\
\hline LC4C & 4 & $1 / 2 b$ & cort & u & no & & 10.1 & 3.9 & 1.8 & 10.1 & crushed & snap fr & gr & mammal \\
\hline LC4d & 4 & $1 / 2 b$ & shaft & u & no & & 10.0 & 2.0 & 1.8 & 7.0 & crushed & complex & $c t / g r$ & mammal \\
\hline LC4e & 4 & $1 / 2 b$ & cort & lb & high & tip & 11.7 & - & 1.8 & - & step fr & complex & gr & mammal \\
\hline LC4f & 4 & $1 / 2 b$ & shaft & calc & no & & 18.7 & 4.4 & 3.4 & 7.8 & intact & snap fr & $g r$ & $\begin{array}{l}\text { Thylogale mid } \\
\text { part fibula }\end{array}$ \\
\hline LC4g & 4 & $1 / 2 b$ & shaft & calc & no & & 22.4 & 7.6 & 3.7 & 22.4 & crushed & snap fr & gг & $\begin{array}{l}\text { Agile Wallaby } \\
\text { distal fibula }\end{array}$ \\
\hline LC4h & 4 & $1 / 2 b$ & cort & $\mathrm{lb}$ & med & tip & 44.6 & 8.0 & 3.3 & 14.5 & intact & snap fr & sh/gr & mammal \\
\hline LC5a & 5 & $1 / 2 b$ & cort & calc & light & ent surf & 17.2 & 6.1 & 2.6 & 17.2 & crushed & sпар fr & gr & mammal \\
\hline LC5b & 5 & $1 / 2 b$ & shaft & $\mathrm{lb}$ & high & tip & 13.2 & 5.7 & 2.2 & 10.9 & intact & snap fr & gr & $\begin{array}{l}\text { Thylogale } \\
\text { distal fibula }\end{array}$ \\
\hline LC16a & 16 & mid & shaft & $\mathrm{lb}$ & no & & 10.7 & 5.6 & 3.2 & & snap fr & snap fr & $g r$ & $\begin{array}{l}\text { Thylogale } \\
\text { distal fibula }\end{array}$ \\
\hline LC24a & 24 & 1 & shaft & U & no & & 28.7 & 4.2 & 2.7 & 14.2 & intact & complex & gr & $\begin{array}{l}\text { Thylogale mid } \\
\text { part fibula }\end{array}$ \\
\hline LC24b & 24 & $1 / 2 b$ & shaft & u & light & ent surf & 4.1 & 1.4 & 0.8 & 4.1 & intact & snap fr & gr & mammal \\
\hline
\end{tabular}

NB: for midsections, 'tip damage' and 'breakage' are both 'type of breakage' at either end

"Legend: 1=unipoint; 2=bipoint; 1/2b=broken uni- or bipoint; spat=spatula; mid=midsection; cort=cortical; u=unburnt; lb=lightly burnt; b=burnt; calc=calcined; med=medium; ent surf= entire surface; snap fr=snap fracture; step fr=step fracture; post-exc=post-excavation; gr=ground; sh/gr= shaved then ground; exp=expedient tool ("all midsections); $\mathrm{ct} / \mathrm{gr}=\mathrm{cut}$ then ground

"Measurements are in $\mathrm{mm}$ 


\begin{tabular}{|c|c|c|c|c|c|c|c|c|c|c|c|c|c|c|}
\hline 訔 & 芸 & $\begin{array}{l}\text { 产 } \\
\text { 幽 }\end{array}$ & 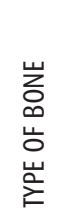 & 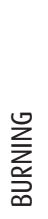 & 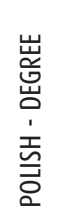 & $\begin{array}{l}\text { zo } \\
\text { 은 } \\
\text { 。 } \\
\text { 志 } \\
\text { 号 }\end{array}$ & 志 & 意 & 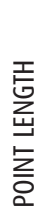 & 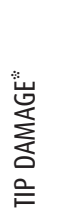 & $\begin{array}{l}\text { 岕 } \\
\text { 紊 } \\
\text { 岕 }\end{array}$ & 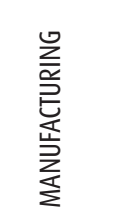 & $\begin{array}{l}\text { 容 } \\
\text { 롰 } \\
\text { 总 }\end{array}$ & $\begin{array}{l}\text { 岂 } \\
\text { 岕 }\end{array}$ \\
\hline $\mathrm{NL} / \mathrm{I} / 12 \mathrm{a}$ & 12 & $1 / 2 b$ & cort & $u$ & no & & 16 & 4.4 & 2.4 & 16 & complex & complex & sh & mammal \\
\hline $\mathrm{NL} / \mathrm{I} / 14 \mathrm{a}$ & 14 & spat & shaft & $\mathrm{lb}$ & high & ent surf & 13.8 & 4.5 & 2.9 & 13.8 & intact & snap fr & gr & mammal \\
\hline NL/I/19a & 19 & $1 / 2 b$ & shaft & $\mathrm{lb}$ & no & & 25 & 5.2 & 3.1 & 11.1 & step fr & step fr & $c t / g r$ & mammal \\
\hline $\mathrm{NL} / \mathrm{I} / 23 \mathrm{a}$ & 23 & spat & shaft & $\mathrm{lb}$ & high & ent surf & 27.8 & 6.1 & 2 & 5.9 & intact & complex & gr & $\begin{array}{l}\text { Thylogale } \\
\text { distal fibula }\end{array}$ \\
\hline $\mathrm{NL} / \mathrm{I} / 26 \mathrm{a}$ & 26 & $1 / 2 b$ & shaft & $\mathrm{lb}$ & light & ent surf & 20 & 4.1 & 2.2 & 5.5 & intact & snap fr & $\mathrm{sh} / \mathrm{gr}$ & mammal \\
\hline $\mathrm{NL} / \mathrm{I} / 27 \mathrm{a}$ & 27 & 1 & shaft & $\mathrm{lb}$ & no & & 34.3 & 5.1 & 2.9 & 34.3 & complex & snap fr & $\mathrm{sh} / \mathrm{gr}$ & $\begin{array}{l}\text { Thylogale } \\
\text { central fibula }\end{array}$ \\
\hline $\mathrm{NL} / \mathrm{I} / 28 \mathrm{a}$ & 28 & $1 / 2 b$ & shaft & $\mathrm{lb}$ & high & tip & 14.7 & 4.5 & 3.6 & 14.7 & intact & step fr & $\mathrm{sh} / \mathrm{gr}$ & \\
\hline $\mathrm{NL} / \mathrm{I} / 28 \mathrm{~b}$ & 28 & exp" & shaft & $u$ & high & ent surf & 25.9 & 1.7 & 1.9 & 25.9 & snap fr & complex & - & snake rib \\
\hline $\mathrm{NL} / \mathrm{I} / 29 \mathrm{a}$ & 29 & 2 & shaft & u & light & ent surf & 43.1 & 5.9 & 3.2 & 14 & intact & intact & $\mathrm{sh} / \mathrm{gr}$ & mammal \\
\hline $\mathrm{NL} / \mathrm{I} / 31 \mathrm{a}$ & 31 & mid & shaft & b & no & & 15.8 & 6.2 & 3.4 & & complex & complex & $\mathrm{sh} / \mathrm{gr}$ & mammal \\
\hline $\mathrm{NL} / \mathrm{I} / 31 \mathrm{~b}$ & 31 & $1 / 2 b$ & shaft & $b$ & no & & 12.8 & 5.4 & 2.7 & 12.8 & intact & snap fr & $\mathrm{sh} / \mathrm{gr}$ & mammal \\
\hline $\mathrm{NL} / \mathrm{I} / 31 \mathrm{C}$ & 31 & $1 / 2 b$ & shaft & $\mathrm{lb}$ & high & tip & 14.8 & 3.8 & 3.2 & 5.5 & intact & snap fr & gr & mammal \\
\hline $\mathrm{NL} / \mathrm{I} / 32 \mathrm{a}$ & 32 & $1 / 2 b$ & cort & $b$ & med & tip & 12 & 4.5 & 1.5 & 12 & intact & snap fr & $\mathrm{sh} / \mathrm{gr}$ & mammal \\
\hline $\mathrm{NL} / \mathrm{I} / 35 \mathrm{a}$ & 35 & $1 / 2 b$ & cort & u & no & & 4.5 & 2.4 & 1.3 & 4.5 & intact & post-exc & $?$ & mammal \\
\hline $\mathrm{NL} / \mathrm{I} / 37 \mathrm{a}$ & 37 & 1 & shaft & u & no & & 38 & 4.6 & 2.5 & 5.8 & crushed & step fr & gr & $\begin{array}{l}\text { Thylogale } \\
\text { central fibula }\end{array}$ \\
\hline
\end{tabular}

NB: for midsections, 'tip damage' and 'breakage' are both 'type of breakage' at either end

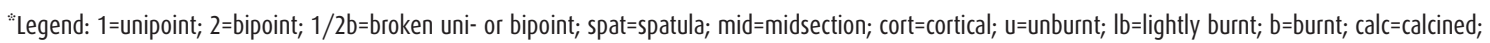
med=medium; ent surf= entire surface; snap fr=snap fracture; step fr=step fracture; post-exc=post-excavation; gr=ground; sh/gr= shaved then ground; exp=expedient tool ("unipoint); $c t / g r=$ cut then ground

"Measurements are in $\mathrm{mm}$

\section{Shaft artefacts: the bipoint}

The only bipointed specimen that was found during the Nabulei Lisa excavations is an asymmetric artefact made of a split long bone, perhaps a tibia or femur of a small or young animal (specimen $\mathrm{NL} / \mathrm{I} / 29 \mathrm{a}$, see Fig. 11.6). It has a total length of $43.1 \mathrm{~mm}$, the long tip measuring $14 \mathrm{~mm}$ and the short tip $7.2 \mathrm{~mm}$. Both tips are intact and the artefact is lightly polished over its entire surface. The width of the artefact is $5.9 \mathrm{~mm}$ and the thickness is $3.2 \mathrm{~mm}$, the latter constituting about half the original thickness of the parent bone.

\section{Shaft artefacts: broken uni- or bipoints}

Five artefacts made of shaft bone were classified as broken uni- or bipoints. Four of these have undamaged tips; one tip bears a step fracture. The butts of these specimens are either snapped off or show step fractures. Two of the undamaged tips show a high polish, the others light to medium or only a very light polish. The artefacts range in length from $12.8-25 \mathrm{~mm}$; the width from $3.8-5.4 \mathrm{~mm}$. The thickness ranges from $2.2-3.6 \mathrm{~mm}$. The point length is variable and ranges from $5.5-14.7 \mathrm{~mm}$; this includes two specimens that are modified over their entire surface, so the actual point length may have been longer.

\section{Shaft artefacts: midsections}

Only one midsection was found in Nabulei Lisa; it is a rather large fragment, perhaps from a rib of a mammal, and it bears clear modification marks. It is $15.8 \mathrm{~mm}$ long, $6.2 \mathrm{~mm}$ wide and $3.4 \mathrm{~mm}$ thick. It is slightly glossy over its entire surface (probably from handling) and is broken at both ends. There are no other artefacts that bear any close resemblance to this fragment. 


\section{Shaft artefacts: spatulae}

Two artefacts have the typical morphology of spatulae: one is a wide artefact with a broad, rounded tip (specimen NL/I/23a, Fig. 11.6), the other is narrower but with an equally smooth, rounded tip (NL/I/14a, Fig. 11.6). The wider specimen was made of the distal part of a Thylogale fibula, the other of an unidentified mammal bone. Both are highly polished and their tips are intact. The fragments are $13.8 \mathrm{~mm}$ and $27.8 \mathrm{~mm}$ long, $4.5 \mathrm{~mm}$ and $6.1 \mathrm{~mm}$ wide, and $2.9 \mathrm{~mm}$ and two millimetres thick, respectively. The shorter artefact is polished to such an extent that it has obliterated most modification marks, making it difficult to establish the point length. The point section of the longer specimen measures $5.9 \mathrm{~mm}$.

\section{Shaft artefacts: the expedient tool}

A thin, curved bone, identifiable as part of a snake rib, bears high polish over its entire surface but otherwise shows no modification marks (specimen NL/I/28b, Fig. 11.6). Although it is classified as an expedient tool, it clearly functioned as an attenuate unipoint. The end of the tip has snapped off. It is $25.9 \mathrm{~mm}$ long, $1.7 \mathrm{~mm}$ wide and $1.9 \mathrm{~mm}$ thick.

\section{Cortical artefacts: broken uni- or bipoints}

Three artefact fragments made of cortical bone could be parts of either unipoints or bipoints. One of these is the very end of a tip and shows no polish. It is only $4.5 \mathrm{~mm}$ long, $2.4 \mathrm{~mm}$ wide and $1.3 \mathrm{~mm}$ thick. The tip itself is intact, but the fragment was broken off some time during or after excavation. The remainder of the artefact has not been located and may be unrecognised amongst the faunal remains.

The other two broken uni- or bipoints are $16 \mathrm{~mm}$ and $12 \mathrm{~mm}$ long, $4.4 \mathrm{~mm}$ and $4.5 \mathrm{~mm}$ wide, and $2.4 \mathrm{~mm}$ and $1.5 \mathrm{~mm}$ thick, respectively. The shorter one has medium polish at its intact tip; the other specimen is unpolished and has its tip broken off. In both cases, the modification marks go beyond the point of breakage, so the original point length could not be established.

\section{Morphological Comparison and Discussion}

Each of the bone artefact assemblages from the Aru sites is highly variable. Because of this, and also because of the relatively small sample size, metrical analysis fails to provide a meaningful basis for comparison. Nevertheless, there are some noteworthy features that need to be discussed, both within and between the assemblages, and between the Aru assemblages and others in the region.

Both sites produced small numbers of attenuate unipoints and spatulae, and larger numbers of artefact fragments, both tips and midsections (or butts). Nabulei Lisa produced the only artefact that could be classified as a bipoint.

Shaft bone was the preferred material for artefact production in both Aru sites, although Nabulei Lisa contained a higher proportion $(80 \%)$ of shaft artefacts than Lemdubu $(70 \%)$. The majority of cortical artefacts, in both sites, are classified as broken uni- or bipoints, the only exception being a spatula from Lemdubu. In the Kria Cave assemblage, from the Bird's Head of Papua, there is a clear distinction in the use of raw material between unipoints and bipoints: bipoints were almost exclusively made of cortical splinters of bone, while attenuate unipoints were mostly made of shaft fragments (Pasveer 2004:175). The same distinction is observed in the two largest samples from the investigated sites in northern Maluku (Siti Nafisah and Golo Cave). Here too, the vast majority of bipoints are made from cortical bone (Pasveer and Bellwood 2004:Table 3), while attenuate unipoints, although fewer in number, are primarily made from shaft fragments. An obvious possibility in regard to the Aru assemblages is that the broken cortical specimens are primarily parts of originally bipointed artefacts. This possibility is explored further below. 
Lemdubu produced bone artefacts that were in most cases $(72.4 \%$, against $28.6 \%$ in Nabulei Lisa) ground into their present shape, while those of Nabulei Lisa were mostly first shaved and then ground (50\%, against $24 \%$ in Lemdubu). However, in both sites the same techniques were applied, albeit in varying combinations, and it is possible that the differences may be explained by the subsequent obliteration of shaving marks on the Lemdubu specimens through excessive grinding.

Around $50 \%$ of the artefacts in both Aru sites were made of lightly burnt bone. Twentyseven per cent and 33\% of the artefacts in Lemdubu and Nabulei Lisa, respectively, was made of unburnt bone. Nabulei Lisa contained a higher proportion of specimens made of burnt bone $(20 \%)$ than Lemdubu (eight per cent). However, the latter site had some calcined artefacts that were, most likely, burnt after deposition, therefore obscuring their original state.

Lightly burnt bone (a state which is usually the result of cooking of the bone) is also the dominant raw material of bone artefacts in Golo Cave in the northern Maluku Province. However, in the absence of information on the burning condition of the wider assemblage, it remains uncertain whether this was due to deliberate selection or simply reflected the availability of raw material at the site (Pasveer and Bellwood 2004). For the Aru sites, we can be more certain that deliberate selection has occurred because, in both sites, unburnt bone was present in higher proportions than lightly burnt bone. The top five spits in Lemdubu (where the majority of bone artefacts were found) contained ca. $43 \%$ unburnt and ca. $41 \%$ lightly burnt bone. In Nabulei Lisa, for the whole deposit (the artefacts were scattered throughout the sequence), these proportions are ca. $57 \%$ and $26 \%$, respectively. These comparisons suggest some moderate preference for lightly burnt bone as raw material for bone artefact production in this area.

Various authors have reported on the qualities of unburnt versus burnt bone for artefact manufacture and use (e.g. Bird and Beeck 1980; Campana 1989; Evans 1973; Guthrie 1983; Knecht 1997; Olsen 1984). Opinions vary somewhat over what constitutes the best kind of bone for this purpose. In general, unburnt or 'green' bone is a hard but flexible raw material but it is said to be difficult to modify. Slightly desiccated bone is said to be better for bone point manufacturing (Bird and Beeck 1980:169). Heating of bone will initially make bone denser and harder; however, excessive heating and burning of bone destroys the organic part of the matrix and renders the bone increasingly brittle (Campana 1989:36).

For the Kria Cave assemblage it was observed that tip-bearing shaft fragments were more consistent in length than shaft midsections (Pasveer 2004:170-1). From this analysis it was concluded that the tip-bearing fragments resulted from breakage during use, rather than through random damage after discard. Because the original artefacts varied in length, the remainder of the tool (i.e. the midsection, which could also simply be the butt of the artefact) also tend to be more variable. The Lemdubu shaft artefacts appear to show the reverse pattern. The shaft midsections (or butts) appear relatively uniform in length, peaking between $7.5-12.5 \mathrm{~mm}$, while the tip-bearing fragments are more variable in length, although the majority also measure between $7.5-12.5 \mathrm{~mm}$. Unfortunately, the sample size is too small to support a statistical analysis and it is not possible to justify any particular conclusion in regard to the breakage pattern.

The presence of predominantly broken specimens at both Aru sites makes it likely that the composite artefacts in which the points were hafted, were subject to maintenance on site, such as replacement or repair. A relatively high incidence of specimens with unpolished and undamaged tips also points to the likely manufacture of bone artefacts on site, leaving behind those that broke during this process. However, the sites produced no obvious examples of unfinished artefacts, such as the cortical splinters with fairly coarsely produced tips and unmodified butts found at Kria and Golo Caves.

The Nabulei Lisa assemblage shows an interesting dichotomy among the tip-bearing artefacts between those with polished and intact tips, and those with unpolished but damaged tips 
(see Table 11.7). In the Lemdubu assemblage, there is no comparable dichotomy between polished and damaged tips (i.e. many artefacts are polished and damaged). The dichotomy between 'no polish - damage' and 'polish - no damage' in the Nabulei Lisa assemblage might be taken as evidence for two different modes of use: one that produced polish but with little risk of damage, and another that carried a risk of damage but did not produce polish. Alternatively, the dichotomy could be between artefacts that either sustained damage shortly after they were brought into use, and others that managed to sustain the rigours of use for long enough to develop polish. With larger samples, it might be possible to test these alternative hypotheses by metrical comparison between the various damage/polish classes.

For the bone artefact assemblages from Kria and Golo Caves, a strong case was made that the bipointed artefacts were hafted as components of composite tools (Pasveer 2004:177-8; Pasveer and Bellwood 2004:130-1). One reason was that many were simply too small to be hand-held (some of the Kria Cave bipoints were only 16mm long; those from Golo Cave as short as $19 \mathrm{~mm}$ ). However, other, no less important evidence came from their polish and breakage patterns. Kria Cave bipoints predominantly bear polish on only one end, despite the fact that, without exception, they are neatly pointed at both ends. This indicates that they were nearly always oriented the same way during repeated use, an outcome that is difficult to reconcile with hand-held use. Furthermore, major breakage was most often found at the secondary end (i.e. the end that showed the least use-wear) of both Kria and Golo bipoints. With hand-held use, breakage is more likely to occur at the end that is under direct pressure (the functional end). In contrast, experimental use of hafted bipoints has shown more consistent breakage at the secondary end where the artefact is under strain within the haft. In combination, these observations support the conclusion that the bipointed artefacts from the sites were frequently hafted for use.

Given this evidence of a regional tradition of bipoint production and composite tool use, it is especially noteworthy that complete or broken bipoints are absent or extremely rare in the Aru sites. Apart from the one complete bipoint from Nabulei Lisa, the only possible evidence for this class of artefacts are fragments classified as 'broken uni- or bipoints'. If originally bipointed, these specimens all snapped at positions before their midpoints and the remaining portion was discarded elsewhere. Moreover, if we assume that the broken uni- or bipoints from Lemdubu (the largest sample) were originally parts of hafted bipoints, then in two-thirds of the 21 cases, it was the functional (polished) end that broke off, rather than the unpolished, hafted end. This observation is the reverse of the pattern observed in both Kria and Golo Cave, where the ends that broke off tend to lack polish or damage. The obvious conclusion is that hafted bipoints of the kind produced in the northern Maluku and Bird's Head sites were not in common use in the Aru Islands through the Late Pleistocene and Holocene. This is not to say that the unipointed artefacts found in the Aru sites were not similarly hafted for use in composite tools. However, there is no direct evidence either for or against this possibility.

The potential function of the bone implements from this region has been extensively discussed in the literature (see for example Lampert 1966; Pasveer 2004; Pasveer and Bellwood 2004; Pickering 1979; Webb 1987). Numerous suggestions have been put forward, based on, or supported by, ethnographic accounts and some by experiments (e.g. Bird and Beeck 1980; Webb 1987). The most frequently described functions are use as arrow or spear tips (e.g. Jones and Johnson 1985:60; Lampert 1966, 1971; McCarthy 1940; Schrire 1982), or as fishing gorges (e.g. Anell 1955; Codrington 1969[1891]:316; Hale and Tindale 1930; Massola 1956:4-5; Mulvaney 1960:77). Other functions, such as ad hoc usage including removing splinters, lancing boils (Blackwood 1950:32), piercing, engraving, or personal adornment (fastening cloaks, nose bones, hairpins) have also been mentioned.

Pasveer (2004) and Pasveer and Bellwood (2004) have discussed the possible function of bone artefacts from the Bird's Head and the northern Maluku Province, drawing on their observations from use-wear (polish) and damage. The presence of high polish on many of the 
specimens, comparable with that observed on many artefacts from the Aru sites, along with damage types such as step fractures, virtually rules out a function as a fish gorge. Step fractures are also unlikely to occur on barbs, since these parts of composite tools usually do not receive any direct impact or pressure on the tip (except perhaps when pulled out, in which case they are more likely to snap). The presence of polish in general suggests a mode of use including repeated friction, and this is unlikely to accumulate on artefacts that are subjected to high velocity impact such as arrow tips or spear points - unless the projectile always hits its target, only penetrates the softer parts of it, and is returned to its owner undamaged (an unlikely scenario). For the Bird's Head and the northern Maluku sites it was concluded that the bone artefacts were most likely used for drilling holes or in engraving activities, the only actions that might generate both polish and damage such as crushing or step fracturing of the tip. This conclusion was strongly supported by a detailed account from the Wola of the Southern Highlands of Papua New Guinea (Sillitoe 1988:64), who use hafted bone points and animal incisors in activities of this kind. Wallaby incisors with obvious use-related damage are present in the Kria Cave assemblage (Pasveer 2004:171-5). A sample of approximately 50 isolated Agile Wallaby incisors from Lemdubu was examined, but none was found to show any convincing sign of use. Wallaby incisors from the faunal assemblage from Golo Cave have not been examined. A more detailed analysis of wallaby and other mammal incisors from all three regions may yield interesting results.

Historical accounts from the Aru Islands indicate that bows and arrows were the main hunting weapons of the Aru people (Merton 1910:60); according to one early observer, they were 'masters of the art' (von Rosenberg 1867:21). Spears were of minor importance. Arrow tips were mostly made of hardwood or iron, although cassowary bone was also used (von Rosenberg 1867:21). These arrows were employed to hunt wild boars and kangaroos. Tips of bamboo were used to hunt for stingrays, and triangular arrows with barbs for fishing (Merton 1910:61). Special blunt tips were used to shoot birds of paradise, so as to catch them alive and undamaged. Leaf veins of sago palms were specifically used to produce small, light arrows with very sharp tips, mostly used by young boys to kill birds. The possible use of bone artefacts as arrowheads in the past therefore warrants further consideration. As mentioned before, the Nabulei Lisa assemblage includes a number of artefacts with unpolished yet damaged tips. This pattern of use wear is consistent with the use of the artefacts as projectile tips. However, more than half of the specimens show no damage at the tips, while others especially in the Lemdubu assemblage, show various combinations of damage and polish, often of quite high intensity. As argued for the northern Maluku and Bird's Head assemblages, the overall pattern of use-wear and damage in the Aru sites, even though based on smaller samples, is more consistent with the option that most specimens were used for drilling or engraving purposes. Obviously, this does not rule out the possibility that some or even many bone artefacts were used for more than one purpose during their functional life.

From available site reports and other publications, it appears that morphologically unspecialised bone artefacts of the kind found in Lemdubu and Nabulei Lisa, are widely distributed through the Indo-Pacific region, from Tasmania, through southeastern, western and northern Australia, across Melanesia (including at least the Bismarck Archipelago, Papua New Guinea and Papua), and west into Indonesia (including northern Maluku, Sulawesi, and Java), the Philippines and mainland Southeast Asia (see, for a review of sites with bone artefacts in Southeast Asia, Olsen and Glover 2004).

Bone artefacts were not only used widely throughout the region but also for a prolonged period of prehistory. Artefacts of this kind have been used from at least ca. 30,000 BP, e.g. Bone Cave in south Tasmania (Webb and Allen 1990) and Niah Cave in Sarawak (Majid 1982). However, most examples come from sites of Late Pleistocene and early Holocene age onwards. In sites where larger numbers of bone artefacts were found, reports mention no change in morphology or parent bone through time (see, for example, Olsen and Glover 2004; Pasveer 2004). 
Liang Lemdubu produced twice as many bone artefacts as Liang Nabulei Lisa in approximately the same period of time. Similarly contrasting rates of bone artefact discard between geographically and temporally related sites seem to be no rarity in this region. For example, Golo Cave on Gebe Island produced 130 bone artefacts, as opposed to one example from another coastal cave, Um Kapat Papo, located $10-15 \mathrm{kms}$ to the east. Kria Cave on the Bird's Head produced 92 specimens against a total of three bone artefacts in contemporary Toé Cave, $12 \mathrm{~km}$ to the southwest. On New Ireland, the inland site of Balof Shelter produced numerous bone artefacts, while contemporaneous coastal sites on the island lack bone artefacts altogether (Downie and White 1978:777-9). Other examples of highly variable discard rates come from sites in the Gunung Sewu area of Central Java (Simanjuntak 2004), and in Victoria, southeastern Australia (Pickering 1979). The significance of these striking contrasts needs to be carefully investigated in each context before any general conclusions can be drawn.

The contrasting sample sizes in the northern Maluku and Bird's Head sites are explained in terms of the function of the site related to the local environment, or the nature of the visiting groups and/or intensity of occupation (Pasveer 2004; Pasveer and Bellwood 2004). Both Aru sites contained vast quantities of faunal remains (although Nabulei Lisa less so than Lemdubu) and its continuing presence throughout the deposit demonstrate that the small sample size of the bone artefact assemblages is neither a matter of preservation nor of infrequent occupation of the sites.

\section{Conclusion}

In general terms, the bone artefacts found at Liang Lemdubu and Liang Nabulei Lisa are similar to those described recently from elsewhere in the eastern Indonesian region (Pasveer 2004; Pasveer and Bellwood 2004). While the Aru sites produced many fragments of unipoints or bipoints and spatulae, complete specimens are extremely rare. The morphology of the Aru bone artefacts seems more variable than those from sites in northern Maluku and Papua provinces, although this may in part reflect the small sample size of the Aru assemblages. Most artefacts were made of sections of small shaft bones, with a more or less intact medullary canal. A smaller proportion was made of splinters of cortical bone, originating from larger long bones. Their manufacturers had a preference for lightly burnt bone, presumably because of its stronger properties compared to fresh, burnt or calcined bone. Grinding was the most frequently applied manufacturing technique, often preceded by shaving.

Due to the relatively low numbers of artefacts, a statistical analysis of metrical attributes was not attempted, however, the distribution and association of use-related polish and damage provided some insights into the potential function of the artefacts, particularly in comparison to the assemblages from Golo Cave and Kria Cave. These comparisons are greatly assisted through application of the same analytical methods in all three studies (Pasveer 2004; Pasveer and Bellwood 2004).

While bone artefacts from Liang Lemdubu show various combinations of polish and damage, those from Liang Nabulei Lisa appear to show a dichotomy between unpolished but damaged specimens and specimens with polish but little or no damage. This could simply be because the intact, polished specimens were higher quality artefacts. However, it is also possible that it is related to a difference in function between the two groups of artefacts. For example, projectile points are unlikely to accumulate polish but might become damaged as a result of highvelocity impacts, whereas those used as drills or engravers are likely to sustain polish rather than damage. Ethnographic sources indicate that the Aru people, at least in historical times, were highly skilled archers (von Rosenberg 1867); this observation is clearly consistent with the possibility that some bone artefacts might have been used as projectile points. 
As noted above, drilling or engraving activities are more likely to produce polished tips as a result of repeated friction. Bone artefacts used in this way may or may not receive damage, such as step fractures or crushing, to the tip. The occurrence of artefacts with similar polish and damage patterns in Golo and Kria Caves, in combination with Sillitoe's (1988:64) detailed account of the Wola in Papua New Guinea using hafted bone artefacts and teeth for drilling or engraving activities, supports the notion that similar activities were carried out in either of the Aru sites. However, wallaby incisors with use-related damage, such as were found in Kria Cave, were not noted during analysis of the Lemdubu fauna. Nabulei Lisa's incisor collection was not examined for this purpose.

An intriguing observation from the Aru bone artefact assemblages is that virtually no complete artefacts were found. The vast majority of specimens in both sites are fragments of artefacts. This probably means that the artefacts were used (and broken) on site. We might assume that repair and replacement were also carried out on site, given that midsections (or butts) also occur. Although undamaged and unpolished specimens were recovered from both sites, it remains uncertain whether actual manufacture took place, since no half-products or 'unfinished' specimens were found.

Another important contrast with the Bird's Head and northern Maluku assemblages is that bipoints are extremely rare in both Aru sites. Only one complete specimen was found, a peculiar artefact from Liang Nabulei Lisa that has the appearance of a bipointed spatula and is unlike any artefact seen in the northern Maluku and Bird's Head collections. In addition, the Aru sites produced no specimens that could be identified as broken bipoints. Of course it is possible that the basal portion of any broken bipoint was meticulously removed from the sites - but is it likely that every single broken bipoint was taken away? Why were the broken unipoints or spatulae not removed? Virtually every other site in the region has produced bipoints, either complete or in broken form. In this light, perhaps the only sensible conclusion is that the occupants of the Aru sites did not regularly manufacture and use bipoints. This (tentative) conclusion that bipointed specimens were not part of the regular bone artefact assemblage in use at Liang Lemdubu and Liang Nabulei Lisa may set the Aru Islands outside of a Late Pleistocene to mid-Holocene cultural area that included the Bird's Head and the northern Maluku Province.

\section{References}

Anell, B. 1955. Contribution to the History of Fishing in the Southern Seas. Uppsala: Almqvist and Wiksells Boktryckeri Ab. Studia Ethnographica Upsaliensia IX.

Arndt, S. and M. Newcomer. 1986. Breakage patterns on prehistoric bone points: an experimental study. In D.A. Roe (ed), Studies in the Upper Palaeolithic of Britain and Northwest Europe, pp. 165-73. BAR International Series 296.

Bird, C. and C. Beeck. 1980. Bone points and spatulae: salvage ethnography in southwest Australia. Archaeology and Physical Anthropology in Oceania 15:168-71.

Blackwood, B. 1950. The Technology of a Modern Stone Age People in New Guinea. Oxford: Oxford University Press. Occasional Papers on Technology 3.

Campana, D.V. 1989. Natufian and Protoneolithic Bone Tools: The Manufacture and Use of Bone Implements in the Zagros and the Levant. Oxford: B.A.R. BAR International Series 494.

Codrington, R.H. 1969[1891]. The Melanesians. Studies in their Anthropology and Folklore. Oxford: Clarendon Press.

Dortch, C.E. 1984. Devil's Lair, a Study in Prehistory. Perth: Western Australian Museum.

Downie, J.E. and J.P. White. 1978. Balof Shelter, New Ireland - Report on a small excavation. Records of the Australian Museum 31:762-802.

Evans, F.G. 1973. Mechanical properties of bone. Springfield: Charles C. Thomas.

Guthrie, R.D. 1983. Osseous projectile points: biological considerations affecting raw material selection and design among Paleolithic and Paleoindian peoples. In J. Clutton-Brock and C. Grigson (eds), Animals and Archaeology. 1. Hunters and Their Prey, pp. 273-94. BAR International Series 163. 
Hale, H.M. and N.B. Tindale. 1930. Notes on some human remains in the Lower Murray Valley. Records of the South Australian Museum 4:145-218.

Johnson, E. 1985. Current developments in bone technology. In M.B. Schiffer (ed.), Advances in Archaeological Method and Theory, 8:157-235. New York: Academic Press.

Jones, R. and I. Johnson. 1985. Rockshelter excavations: Nourlangie and Mt Brockman Massifs. In R. Jones (ed.), Archaeological Research in Kakadu National Park, pp. 39-76. Canberra: Australian National Parks and Wildlife Service. Special Publication 13.

Knecht, H. 1997. Projectile points of bone, antler, and stone. Experimental explorations of manufacture and use. In H. Knecht (ed.), Projectile Technology, pp. 191-212. New York: Plenum Press.

Lampert, R.J. 1966. An excavation at Durras North, New South Wales. Archaeology and Physical Anthropology in Oceania 1:83-118.

Lampert, R.J. 1971. Burrill Lake and Currarong: Coastal Sites in Southern New South Wales. Canberra: Department of Prehistory, Research School of Pacific Studies and Asian Studies, Australian National University. Terra Australis 1.

Majid, Z. 1982. The west mouth, Niah, in the prehistory of Southeast Asia. Sarawak Museum Journal (N.S.) 31:1-200. Special Monograph 3.

Massola, A. 1956. Australian fish hooks and their distribution. National Museum of Victoria, Memoirs 22:1-16. Anthropology Series 1.

McCarthy, F.D. 1940. The bone point, known as Muduk, in eastern Australia. Records of the Australian Museum 20:313-9.

Merton, H. 1910. Forschungsreise in den Sudostlichen Molukken (Aru- und Kei Inseln). Frankfurt am.M.: Senckenbergischen Naturforschenden Geschellschaft.

Mulvaney, D.J. 1960. Archaeological excavations at Fromm's Landing on the lower Murray Valley, South Australia. Proceedings of the Royal Society of Victoria 72:53-85.

Olsen, S.L. 1984. Analytical Approaches to the Manufacture and Use of Bone Artifacts in Prehistory. Unpublished PhD thesis, University of London, London.

Olsen, S.L. and I.C. Glover. 2004. The bone industry of Ulu Leang 1 and Leang Burung 1 rockshelters, Sulawesi, Indonesia, in its regional context. In S.G. Keates and J.M. Pasveer (eds), Quaternary Research in Indonesia, pp. 273-99. Leiden: A.A. Balkema Publishers. Modern Quaternary Research in Southeast Asia 18.

Pasveer, J.M. 2004. The Djief Hunters: 26,000 Years of Rainforest Exploitation on the Bird's Head of Papua, Indonesia. Lisse: A.A. Balkema. Modern Quaternary Research in Southeast Asia 17.

Pasveer, J.M. and P. Bellwood. 2004. Prehistoric bone artefacts from the northern Moluccas, Indonesia. In S.G. Keates and J.M. Pasveer (eds), Quaternary Research in Indonesia, pp. 301-59. Lisse: A.A. Balkema Publishers. Modern Quaternary Research in Southeast Asia 18.

Pearce, J. and R. Luff. 1994. The taphonomy of cooked bone. In R. Luff and P. Rowley-Conwy (eds), Whither Environmental Archaeology?, pp. 51-6. Oxford: Oxbow Books. Oxbow Monograph 38.

Pickering, M.P. 1979. Aboriginal Bone Tools from Victoria. Unpublished B.A. Honours thesis, La Trobe University, Melbourne.

von Rosenberg, C.B.H. 1867. Reis Naar de Zuidoostereilanden Gedaan in 1865 op last der Regering van Nederlandsch-Indie. 's-Gravenhage: Martinus Nijhoff.

Schrire, C. 1982. The Alligator Rivers: Prehistory and Ecology in Western Arnhem Land. Canberra: Department of Prehistory, Research School of Pacific Studies and Asian Studies, Australian National University. Terra Australis 7.

Shipman, P., G. Foster, and M. Schoeninger. 1984. Burnt bones and teeth: an experimental study of color, morphology, crystal structure and shrinkage. Journal of Archaeological Science 11:307-25.

Sillitoe, P. 1988. Made in Niugini: Technology in the Highlands of Papua New Guinea. London: British Museum Publications.

Simanjuntak, T. 2004. New insight on the prehistoric chronology of Gunung Sewu, Indonesia. In S.G. Keates and J.M. Pasveer (eds), Quaternary Research in Indonesia, pp. 9-30. Leiden: A.A. Balkema Publishers. Modern Quaternary Research in Southeast Asia 18.

Ubelaker, D.H. 1978. Human Skeletal Remains. Chicago: Aldine Publishing Co.

Webb, C. 1987. Use-Wear on Bone Tools: An Experimental Program and Three Case-Studies from South-East Australia. Unpublished Honours thesis, La Trobe University, Melbourne.

Webb, C. and J. Allen. 1990. A functional analysis of Pleistocene bone tools from two sites in Southwest Tasmania. Archaeology in Oceania 25:75-8. 